\title{
Emilin-2 is a component of bone marrow extracellular matrix regulating mesenchymal stem cell differentiation and hematopoietic progenitors
}

\author{
Francesco Da Ros ${ }^{1,2}$, Luca Persano ${ }^{3,4}$, Dario Bizzotto ${ }^{2}$, Mariagrazia Michieli ${ }^{5}$, Paola Braghetta ${ }^{2}$, \\ Mario Mazzucato ${ }^{1}$ and Paolo Bonaldo $2,6^{*}$ (D)
}

\begin{abstract}
Background: Dissection of mechanisms involved in the regulation of bone marrow microenvironment through cellcell and cell-matrix contacts is essential for the detailed understanding of processes underlying bone marrow activities both under physiological conditions and in hematologic malignancies. Here we describe Emilin-2 as an abundant extracellular matrix component of bone marrow stroma.

Methods: Immunodetection of Emilin-2 was performed in bone marrow sections of mice from 30 days to 6 months of age. Emilin-2 expression was monitored in vitro in primary and mesenchymal stem cell lines under undifferentiated and adipogenic conditions. Hematopoietic stem cells and progenitors in bone marrow of 3- to 10-month-old wildtype and Emilin-2 null mice were analyzed by flow cytometry.

Results: Emilin-2 is deposited in bone marrow extracellular matrix in an age-dependent manner, forming a meshwork that extends from compact bone boundaries to the central trabecular regions. Emilin-2 is expressed and secreted by both primary and immortalized bone marrow mesenchymal stem cells, exerting an inhibitory action in adipogenic differentiation. In vivo Emilin-2 deficiency impairs the frequency of hematopoietic stem/progenitor cells in bone marrow during aging.
\end{abstract}

Conclusion: Our data provide new insights in the contribution of bone marrow extracellular matrix microenvironment in the regulation of stem cell niches and hematopoietic progenitor differentiation.

Keywords: Extracellular matrix, Bone marrow, Mesenchymal stem cells, Emilin-2

\section{Introduction}

Bone marrow $(\mathrm{BM})$ is a heterogeneous tissue involved in hematopoiesis. Although hematopoietic stem cells (HSC) exert the main role in repopulating immune cells and all blood lineages, their activity can be modulated

*Correspondence: bonaldo@bio.unipd.it

2 Department of Molecular Medicine, University of Padova, Via Ugo Bassi 58/B, 35131 Padova, Italy

Full list of author information is available at the end of the article by different factors related to $\mathrm{BM}$ microenvironment. Mesenchymal stem cells (MSC), osteoblasts, adipocytes, endothelial cells, cytokines and extracellular matrix (ECM) proteins provide a number of signals modulating HSC function in BM. Literature work highlighted the importance of BM-MSC [1] and the proper balance between osteogenic and adipogenic differentiation, which can influence in opposite ways HSC function and activity [2-5]. original author(s) and the source, provide a link to the Creative Commons licence, and indicate if changes were made. The images or other third party material in this article are included in the article's Creative Commons licence, unless indicated otherwise in a credit line to the material. If material is not included in the article's Creative Commons licence and your intended use is not permitted by statutory regulation or exceeds the permitted use, you will need to obtain permission directly from the copyright holder. To view a copy of this licence, visit http://creativecommons.org/licenses/by/4.0/. The Creative Commons Public Domain Dedication waiver (http://creativeco mmons.org/publicdomain/zero/1.0/) applies to the data made available in this article, unless otherwise stated in a credit line to the data. 
The importance of MSC in the maintenance of BM homeostasis is further highlighted by several pathological conditions in which these cells can be modulated by tumor cells, like multiple myeloma or leukemia cells, to mold a tumor-supporting microenvironment through secretion of exosomes and matrix metalloproteinases or modification of osteogenic/adipogenic potential [6-8]. Alterations of BM microenvironment occur not only in multiple myeloma and leukemia, but also in myelodysplastic syndromes (MDS), a heterogeneous group of disorders characterized by anomalous growth of HSC and their abnormal differentiation in hematopoietic progenitor cells (HPC) as common myeloid progenitors (CMP), granulocyte myeloid progenitors (GMP) and megakaryocyte-erythrocyte progenitors (MEP) [9]. In particular, studies aimed at the characterization of hematopoietic stem and progenitor cell populations in MDS patients correlating with the risk of acute myeloid leukemia (AML) revealed an increased number of HSC and CMP coupled with a decreased amount of GMP in MDS with low risk of AML, whereas an expansion of GMP was observed in patients with high risk of AML onset [10-12].

It has been established that the ECM compartment of $\mathrm{BM}$ includes proteoglycans, collagens, fibronectin and tenascin-C [13-19], and that these ECM components influence both normal hematopoiesis and the development of hematological malignancies, such as lymphoma, leukemia and multiple myeloma (reviewed in [20]. Interestingly, recent studies of the matrisome [21] of AML patients highlighted a number of ECM-related genes with potential involvement in tumor onset and progression [22, 23]. Among these, EMILIN2, a gene coding for an ECM glycoprotein of the Emilin/Multimerin family [24, 25], belonged to the group of most deregulated genes in AML patients when compared to healthy donors [23]. Notably, independent studies demonstrated that Emilin-2 plays a critical role in modulating tumor cell apoptosis and angiogenesis [26-28].

Starting from these literature evidence, we investigated the role of Emilin-2 in murine BM, taking advantage of the availability of an Emilin2 null mouse model. Our results indicate that Emilin-2 is a key component of murine BMECM involved in MSC and hematopoietic differentiation in an age-dependent manner.

\section{Results}

Emilin-2 is an ECM component of adult mouse BM

Immunofluorescence microscopy of frozen sections of decalcified femurs and tibiae of 1- to 6-month-old mice showed that Emilin-2 is deposited in the BM stroma (Fig. 1A-L). A strong Emilin-2 signal was displayed by the diaphyseal regions of both femur (Fig. $1 \mathrm{H}$ ) and tibia (Fig. 1K), starting from the endosteal region to central vessel area (Additional file 1: Fig. S1A), but not in compact bone (Fig. 1M; Additional file 1: Fig. S1A). Emilin-2 deposition in BM-ECM increased during postnatal life, as shown by staining at 1, 3 and 6 months (Fig. 1B, $\mathrm{E}, \mathrm{H})$,forming a meshwork that partially co-localized with Collagen IV, a well characterized BMECM protein, and surrounding various sets of cells (Fig. 1C, F, I). As expected, Emilin-2 staining was absent in BM sections of Emilin2 null mice (Fig. 1N, O; Additional file 1: Fig. $\mathrm{S} 1 \mathrm{E})$, thus confirming the specificity of the immunolabeling. Interestingly, Emilin-2 labeling in BM resembled Collagen IV deposition [16], but also showed a distinctive pattern, since Collagen IV staining surrounded arteriolar vessels and sinusoids (Fig. 1A, D, G, J), whereas Emilin-2 signal was absent in both structures(Fig. 1C, F, I, L). Higher magnifications confirmed that Emilin-2 deposition in sinusoids and vessels was found in the proximity of Collagen IV staining, but did not co-localize with it (Additional file 1: Fig. S1B-D).

\section{Emilin- 2 is expressed by MSC and is down-regulated during adipogenic differentiation}

Within BM microenvironment, MSC are major actors in regulating $\mathrm{BM}$ homeostasis [4]. In particular, the unbalance toward adipogenic differentiation of BM-MSC, which can occur during aging or pathological conditions, negatively impacts HSC quiescence, proliferation and differentiation [2, 3, 5]. The abundant deposition of Emilin-2 in BM ECM prompted us to investigate its expression in stromal BM cells, and in particular in MSC under undifferentiated and differentiated conditions. Using the ST2 cell line as a surrogate of murine BM-MSC [29], we evaluated Emilin-2 expression at the RNA and protein levels

(See figure on next page.)

Fig. 1 Emilin-2 distribution in BM of adult mice. A-I Representative immunofluorescence for Emilin-2 (red) and Collagen IV (gray) in BM of femur of 1-month-old (A-C), 3-month-old (D-F) and 6-month-old (G-I) wild-type mice. Asterisks in panel I indicate sinusoids and vessels. $\mathbf{J}-\mathbf{L}$ Representative immunofluorescence for Emilin-2 (green) and Collagen IV (gray) in BM of tibia of 6-month-old wild-type mice. Asterisks in panel L indicate sinusoids and vessels. $\mathbf{M}$ Whole-mount immunofluorescence staining for Emilin-2 (green) in BM of femur of 6-month-old wild-type mice. BM and compact bone areas are indicated. $\mathbf{N}, \mathbf{O}$ Representative immunofluorescence for Emilin-2 (green) and Collagen IV (gray) in BM of femur of 6-month-old Emilin2 null mice. In panels C, F, I, M, O, nuclei were stained with Hoechst (blue). Scale bar, 100 m. Col IV, Collagen IV. See also Additional file 1: Fig. S1 

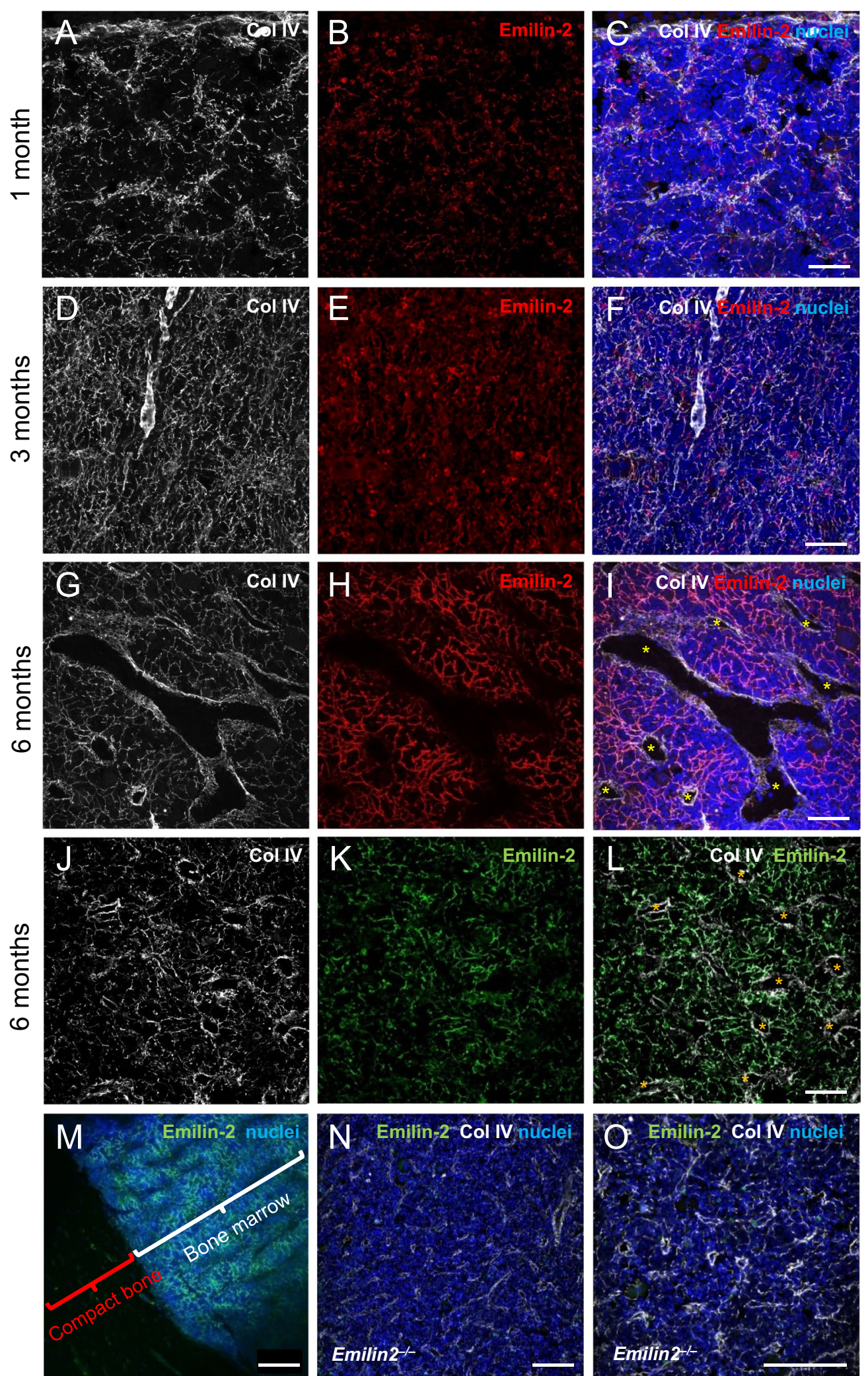

N Emilin-2 Col IV nuiclei

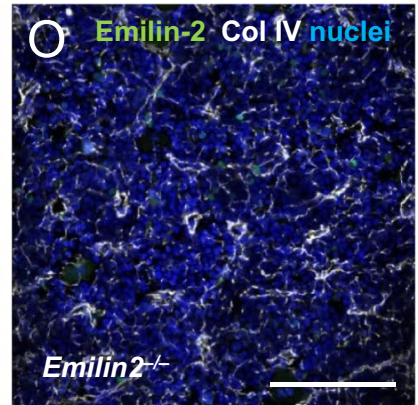

Fig. 1 (See legend on previous page.) 
both in non-differentiating conditions and following adipogenic differentiation (Fig. 2A-D). ST2 cells maintained under non-differentiating conditions displayed a progressive increase of Emilin-2 mRNA and protein levels during culture (Fig. 2B-D). To assess whether Emilin-2 expression is modulated during MSC differentiation, we administered adipogenic stimuli for 3 and 7 days. Emilin-2 mRNA and protein levels rapidly decreased during the first days of differentiation (Fig. 2B-D), in parallel with the concurrent increase of adipogenic markers (Fig. 2A, C). Indeed, while the adipogenic markers AdipoQ, C/EBP-alpha, and FABP4 were increasing at both 3 and 7 days of differentiation, Emilin-2 displayed a marked decrease at day 3 , and even more at day 7 of differentiation (Fig. 2B, C). Immunostaining of ST2 cultures confirmed that Emilin-2 deposition increased and became progressively more abundant during non-differentiating conditions, but was very low following adipogenic differentiation (Fig. 2D).

Although this set of data indicated that Emilin-2 expression is reduced during adipogenic differentiation, in the above experiments we started treating cells one day after plating, when Emilin-2 deposition is still low (Fig. 2D, t0 condition; Additional file 1: Fig. S2A). To understand whether Emilin-2 is down-regulated during adipogenesis, we induced adipogenic differentiation after 3 days from plating (Additional file 1: Fig. S2B), a time point in which Emilin-2 expression is much higher in undifferentiated ST2 cells (Additional file 1: Fig. S2C). Again, adipogenic differentiation was confirmed by the increased expression of AdipoQ and FABP4 following administration of adipogenic stimuli (Fig. 2E). Notably, Emilin-2 mRNA levels were high in undifferentiating conditions but decreased of about $80 \%$ after 3 and 7 days of adipogenic differentiation (Fig. 2F), supporting the concept that Emilin2 expression is down-regulated during adipogenic differentiation. To assess whether Emilin2 was down-regulated due to a potentially inhibitory effect it may exert on adipogenesis, we cultured ST2 cells in the presence of purified Emilin-2, added in the culture medium one day before starting the experiment (Additional file 1: Fig. S2D). Of note, pre-treatment of cells with Emilin-2 led to significantly decreased levels of AdipoQ and FABP4 transcripts after 3 days from adipogenic differentiation, when compared to cells maintained in the same conditions but without Emilin-2 (Fig. 2G),thus supporting an inhibitory effect for Emilin-2 on the adipogenic differentiation of BM-MSC.

\section{Primary BM-MSC regulate Emilin2 expression and deposition during adipogenesis}

To further understand the modulation of Emilin-2 expression during MSC differentiation, we studied primary BM-MSC isolated from wild-type mice. After three passages to reduce the presence of contaminating leukocytes, we first confirmed the capability of these cells to differentiate in the presence of adipogenic stimuli for different times (Additional file 1: Fig. S2E). Culture of primary BM-MSC in adipogenic differentiation medium for 3 to 10 days led to a marked increase of AdipoQ and FABP4 at both mRNA and protein levels, when compared to cells maintained in non-differentiating conditions (Fig. 3A, C). As with ST2 cultures, Emilin-2 was expressed by primary undifferentiated BM-MSC and its deposition became more abundant during culture (Fig. 3B-D). At difference from ST2 cells, Emilin-2 mRNA levels increased during the first days of adipogenic differentiation, whereas a trend toward down-regulation of Emilin-2 mRNA levels was observed only after 10 days of adipogenic differentiation (Fig. 3B). However, immunodetection of Emilin-2 protein in BM-MSC at day 3 of culture in adipogenic differentiation medium revealed a weaker extracellular staining when compared to cultures maintained in standard medium (Fig. 3D).

\footnotetext{
(See figure on next page.)

Fig. 2 Emilin-2 expression in ST2 cells during in vitro adipogenic differentiation. A mRNA levels of adipogenic markers in ST2 cells under non-differentiating conditions (UT t3) or after 3-7 days of treatment with adipogenic stimuli (Adipo t3 and t7), as determined by RT-qPCR. mRNA levels are shown as fold change compared to UT t3 condition $\left(n=3-9 ;{ }^{*} p<0.05 ;{ }^{* *} P<0.01\right.$; $\left.{ }^{* *} P<0.001\right)$. B RT-qPCR analysis of mRNA levels of Emilin-2 in ST2 cells under non-differentiating conditions (UT t0 and t3) and after 3 and 7 days of treatment with adipogenic stimuli (Adipo t3 and t7). mRNA levels are shown as fold change compared to UT t0 condition ( $\left.n=3-9 ;{ }^{*} P<0.05 ;{ }^{* *} P<0.001\right)$. C Western blot analysis for Emilin-2, AdipoQ and FABP4 proteins in ST2 cells under non-differentiating condition (UT t0 and t3) and after 3 days of adipogenic stimuli (Adipo t3). Three independent samples are shown for each condition. $\beta$-actin was used as a protein loading control. The graph on the right show densitometric quantification for Emilin-2, as determined by two independent experiments. Protein levels are shown as fold change compared to UT t3 condition ( $\left.n=3-6 ;{ }^{*} P<0.05 ;{ }^{* *} P<0.01\right) \mathbf{D}$ Immunofluorescence for Emilin-2 (green) in ST2 cells at 0, 3 and 7 days culture in untreated conditions (UT) or in the presence of adipogenic stimuli (Adipo). Nuclei were stained with Hoechst (blue). Scale bar, 100 Hm. E, F RT-qPCR analysis of the mRNA levels for AdipoQ, FABP4 (E) and Emilin-2 (F) in ST2 cells cultured for 3 days before adipogenic treatment (day 3, UT t0) and then treated for 3 and 7 days with adipogenic stimuli (day 3, Adipo t3 and t7). mRNA levels are shown as fold change compared to day 3 , UT t0 condition $\left(n=3\right.$; $\left.{ }^{* *} P<0.001\right)$. G Relative mRNA levels of AdipoQ and FABP4 in ST2 cells cultured under non-differentiating conditions (UT t3) or after 3 days of adipogenic stimulus in cells pre-treated (Adipo + E2 t3) or not (Adipo t3) with purified Emilin-2 protein. mRNA levels are shown as fold change compared to UT t3 condition $\left(n=3 ;{ }^{* *} P<0.01 ;{ }^{* *} P<0.001\right)$. See also Additional file 1: Figs. S1 and S2
} 
A

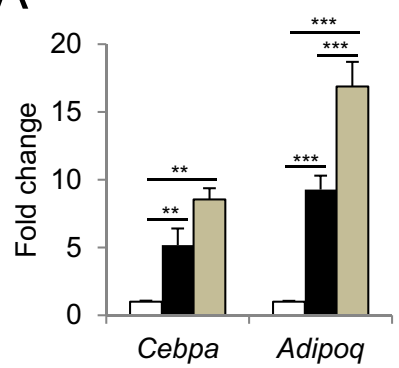

C

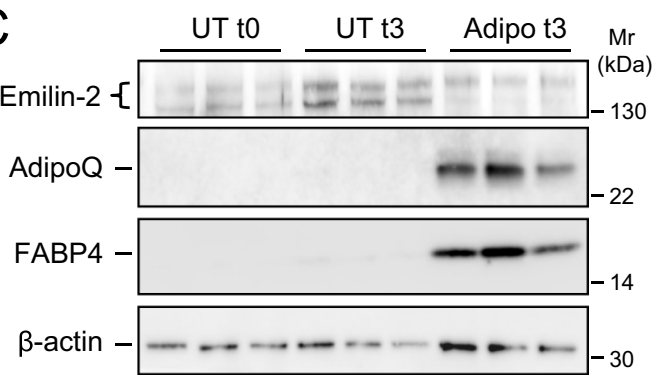

D
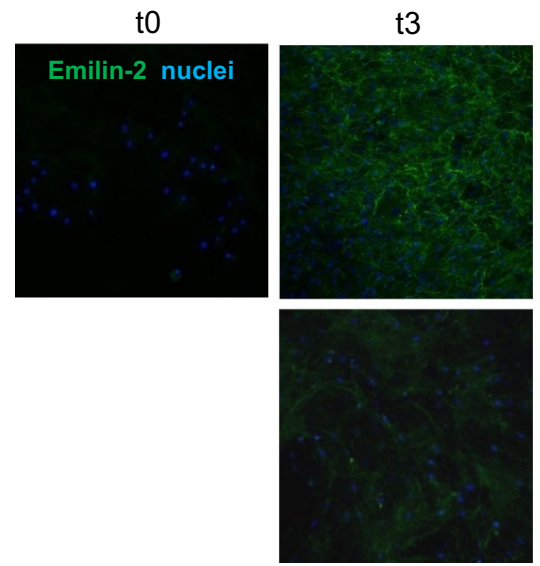

E

F
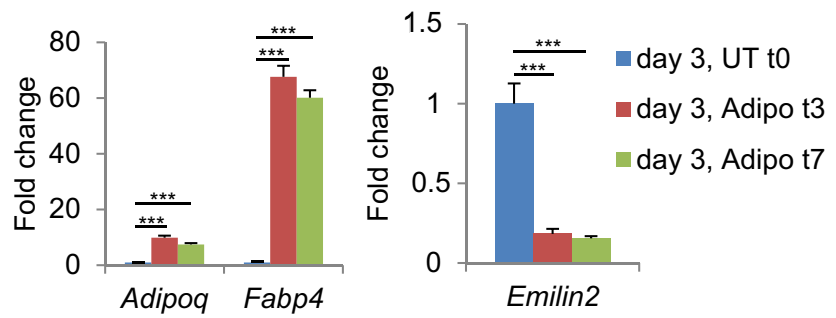

B
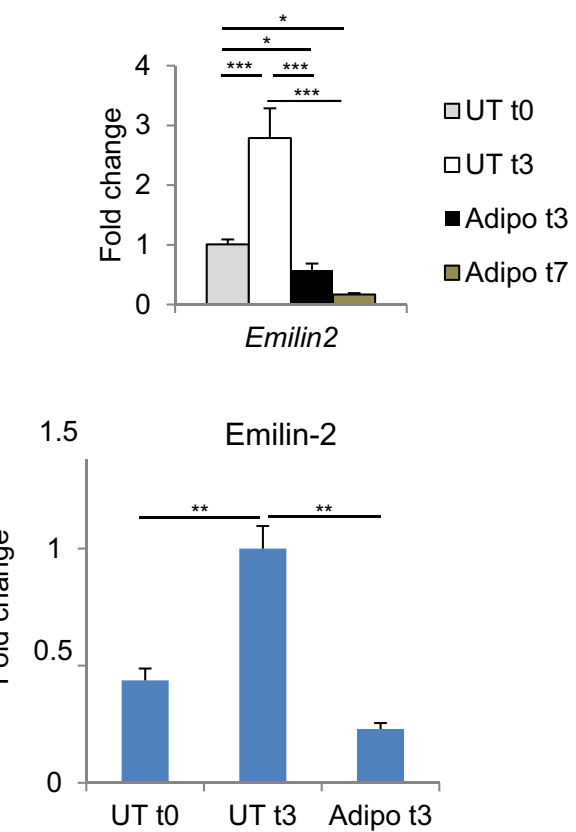
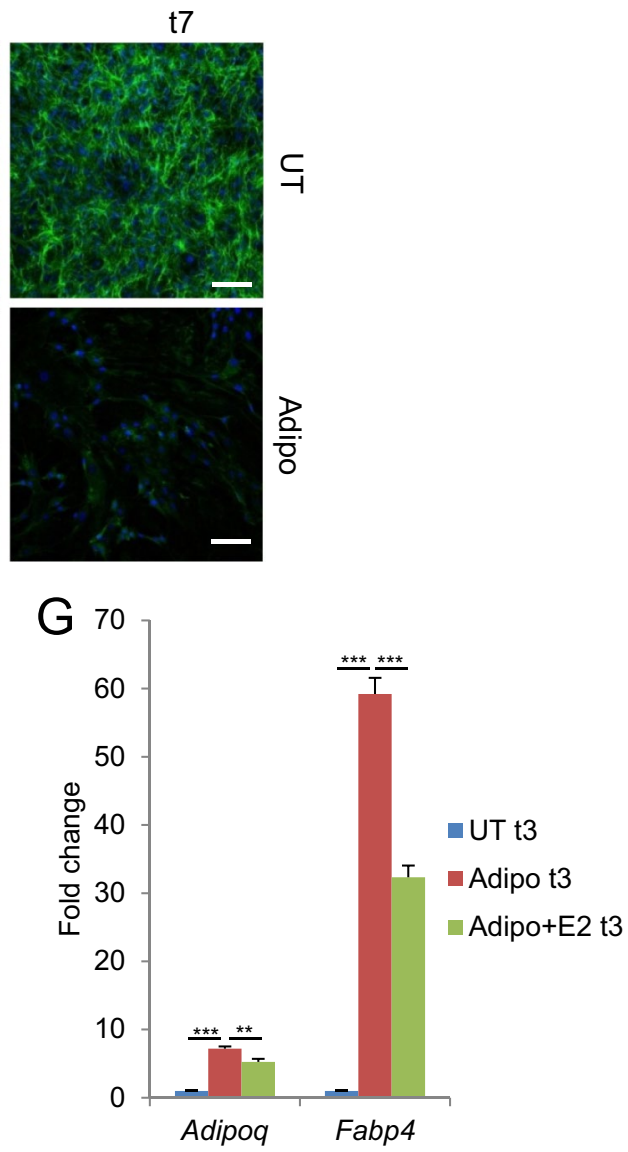

Fig. 2 (See legend on previous page.) 
Cell permeabilization before immunostaining showed the presence of intracellular Emilin-2 positive dots in differentiating BM-MSC cultures (Fig. 3E), and immunodetection at longer times of differentiation confirmed the drop in Emilin-2 levels (Additional file 1: Fig. S3). These data indicate that Emilin-2 deposition is down-regulated in primary BM-MSC during adipogenic differentiation but, at difference from immortalized ST2 cells, the first step in modulation of Emilin-2 levels is a decrease in protein secretion, followed by a progressive drop in gene expression and protein deposition.

\section{In vivo ablation of Emilin-2 impairs HSC pool and affects the differentiation of hematopoietic precursors during aging}

Several literature data have linked abnormal HSC differentiation and altered distribution of hematopoietic progenitors in BM with alterations of ECM microenvironment (reviewed in [30]. Based on the abundant deposition of Emilin-2 in BM ECM, and taking advantage of the availability of an Emilin-2 null $\left(\right.$ Emilin $\left.^{-/}\right)$ mouse model [28], we investigated whether the absence of this protein may affect the frequency of hematopoietic stem cells (HSC) and of hematopoietic progenitor cells (HPC)-including common myeloid progenitors (CMP), granulocyte myeloid progenitors (GMP) and megakaryocyte-erythrocyte progenitors (MEP)-during adulthood. Using a cytometric approach based on specific markers for the various classes of hematopoietic progenitors (Additional file 1: Fig. S4), we detected a progressive change in HSC and progenitor populations from 3 to 10 months of age in Emilin $2^{-1-}$ mice, when compared to age-matched wild-type mice (Figs. 4A-C, $5 \mathrm{~A}-\mathrm{C}$ ). At 3 months of age, no differences were observed in the frequency of cell populations (Figs. 4B, 5B), while at 6 months Emilin2 ${ }^{-/-}$BM displayed a trend toward decreased HSC pool versus lineage-negative (Lin-) population, but not versus total live cells(Fig. 4B). At
10 months of age, Emilin2 $2^{-/-}$mice showed a dramatic decrease of HSC, CMP and MEP frequencies and a trend toward a reduction of GMP abundance in Linpopulation(Figs. 4B, 5C),pointing at an impairment in the maintenance of the proper pool of hematopoietic progenitors and an unbalance in the differentiation process.

Further characterization of the HSC subpopulation revealed that 10 -month-old Emilin2 ${ }^{-1-}$ mice have higher frequencies of long term-(LT)-HSC among live cells, total HSC and Lin-cells (Fig. 4C). Moreover, the decrease of the HSC pool in Lin- subpopulation, but not in total live cells, was associated with a progressive increased frequency of Lin- cells in Emilin $2^{-I-}$ BM from 3 to 10 months of age (Fig. 5B, C). These data, combined with a significant decreased frequency of CD45+ cells in 10-month-old Emilin2 ${ }^{-1}$ BM (Fig. 6), supported the concept of progressive impairment of differentiation in the hematopoiesis process. In agreement with this, further analyses with lymphoid and myeloid differentiation markers revealed significantly decreased amounts of $\mathrm{CD} 11 \mathrm{~b}+$ (monocyte/macrophage) and CD3+ ( $\mathrm{T}$ cell $)$ pools, but not of Ter119+ (erythroid) and B220+ (B cell) pools, in BM of 10-month-old Emilin2 $2^{-1-}$ mice (Fig. 6).

These findings suggested a possible link between the altered frequencies of HSC and progenitors in Emilin-2 null BM and Emilin-2 expression in the respective lineages. Interestingly, analysis of three human gene expression datasets in the hematopoietic lineage (GSE17054/ GSE19599, GSE24759 and GSE42519) revealed that CMP and GMP, two of the HPC populations with decreased frequencies in 10-month-old Emilin2 ${ }^{-/}$BM, express higher level of Emilin-2 when compared to HSC and MEP (Fig. 7).

\section{Discussion}

The BM microenvironment is essential for regulating hematopoiesis and involves several players belonging to both cell and ECM compartments. The cell compartment

(See figure on next page.)

Fig. 3 Emilin-2 expression during in vitro adipogenic differentiation of primary BM-MSC. A, B RT-qPCR analysis of the mRNA levels for the adipogenic markers AdipoQ (A, left) and FABP4 (A, right) or for Emilin-2 (B) in primary murine BM-MSC under non-differentiating conditions (UT t3) or treated for 3, 7 and 10 days with adipogenic stimuli (Adipo t3, t7 and t10). mRNA levels are shown as fold change compared to UT t3 condition $\left(n=6 ;{ }^{*} P<0.05 ;{ }^{*} P<0.01 ;{ }^{* * *} P<0.001\right)$. C Western blot analysis for Emilin-2, AdipoQ and FABP4 proteins in primary murine BM-MSC under non-differentiating conditions (UT t3) and after 3 days of adipogenic differentiation (Adipo t3). Three independent samples are shown for each condition. $\beta$-actin was used as a protein loading control. The graph on the right show the densitometric quantification for Emilin-2, as determined by two independent experiments. Protein levels are shown as fold change compared to UT t3 condition $(n=4 ; * P<0.05)$. D Representative immunofluorescence for Emilin-2 (green) in primary murine BM-MSC cultures in control conditions (UT t0) and after 3 days in non-differentiating (UT t3) or adipogenic differentiating (Adipo t3) conditions. Scale bar, $100 \mu \mathrm{m}$. Nuclei were stained with Hoechst (blue). E Immunofluorescence for Emilin-2 (green) in primary murine BM-MSC cultures maintained for 3 days in non-differentiating (UT t3) or adipogenic differentiating (Adipo t3) conditions, and subjected to permeabilization with Triton X-100 before immunostaining. In non-differentiating conditions, most Emilin-2 labeling is found in the ECM in the form of an organized fibrillar network, whereas in cultures subjected to adipogenic differentiation Emilin-2 reactivity is found inside the cells in the form of dots scattered throughout the cytosol. Nuclei were stained with Hoechst (blue). Scale bar, $100 \mu \mathrm{m}$. See also Additional file 1: Figs. S1, S2 and S3 

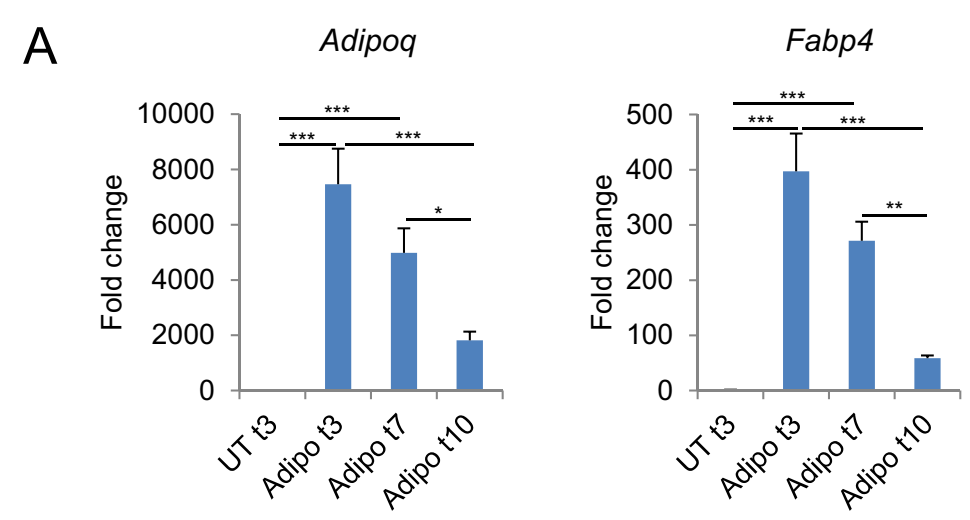

B

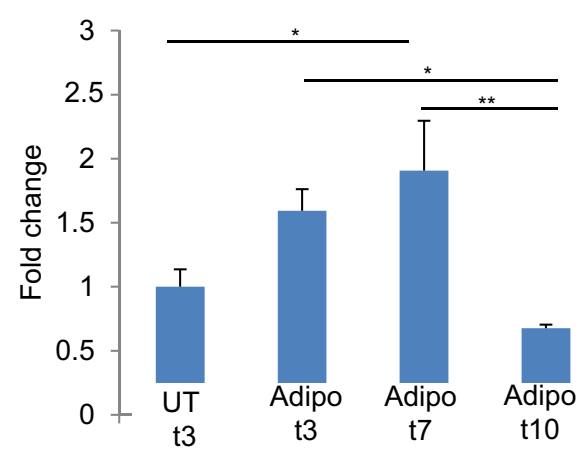

C

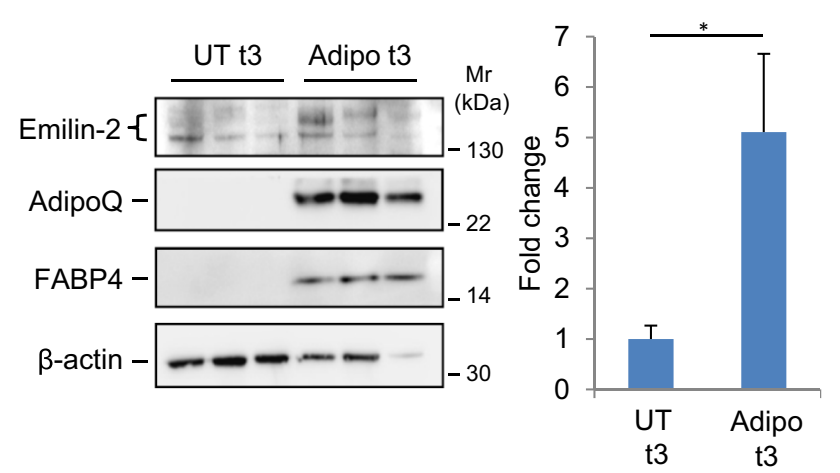

D

UT to

UT t3

Adipo t3
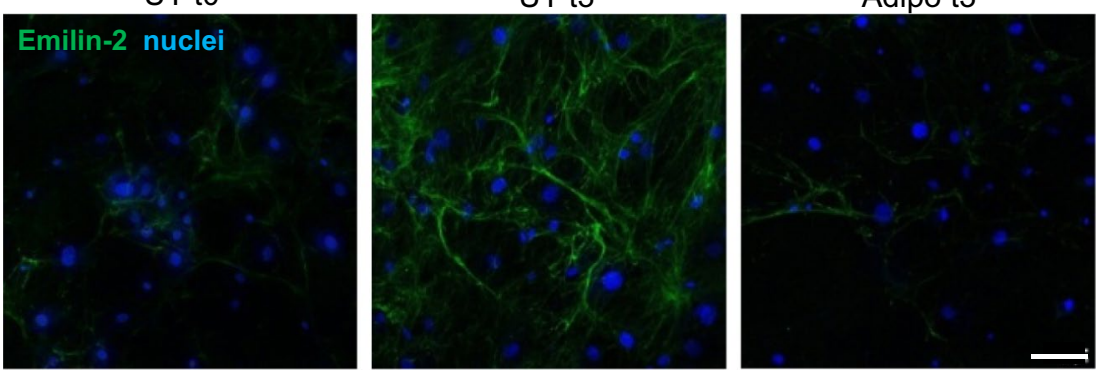

E

UT t3

Adipo t3
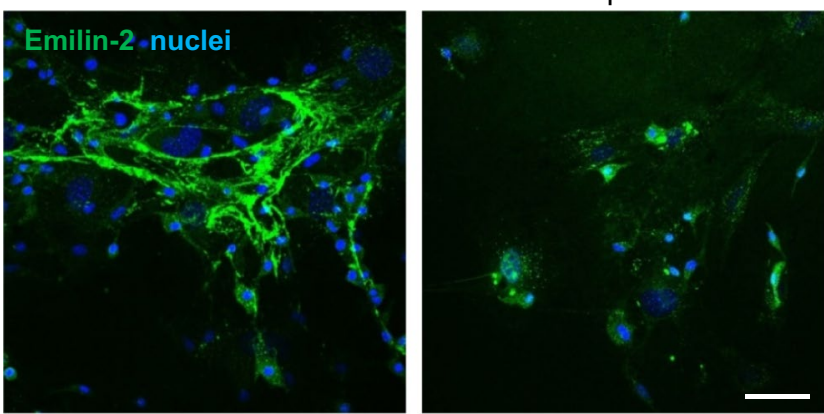

Fig. 3 (See legend on previous page.) 
includes a wide heterogeneity of hematopoietic and stromal cells, such as HSC, HPC, MSC, osteolineage cells, adipocytes, endothelial/sinusoidal cells and immune cells, whose roles in regulating BM homeostasis and HSC niche has been well understood in recent years (for reviews, see [31-33]. Conversely, knowledge about the ECM compartment is still scant and largely based on older studies carried out in the last century [13-15, $18,19]$, with only few most recent findings $[16,17,34]$. In particular, although the impact of ECM in influencing BM functions is increasingly recognized, there is still scarce information about the role of specific ECM components in the regulation of $\mathrm{BM}$ homeostasis.

In this study, we show that Emilin-2, an ECM protein belonging to the Emilin/Multimerin family [24, 25], is a distinctive component of murine $\mathrm{BM}$ microenvironment and exerts a role in modulating hematopoiesis and MSC differentiation. Our data show that Emilin-2 is present in the ECM of both femur and tibia with a distinctive pattern, which extends from the endosteal district to the central region of BM. Interestingly, the Emilin-2 matrix network surrounds group of cells of different types and shapes, recapitulating in part Collagen IV matrix deposition [16], but with the exclusion of vessels and sinusoids.

To explore the role of Emilin-2 in BM, we characterized its expression and secretion by MSC, considering the role of MSC in modulating BM homeostasis through the balance between osteogenic and adipogenic differentiation $[2,3,5]$. Our data show that not only Emilin-2 is expressed and secreted by both ST2 MSC cell line and primary BM-derived MSC, but it also exerts a remarkable effect in modulating adipogenic differentiation. Indeed, we found that Emilin-2, besides being down-regulated and decreased in the ECM of MSC undergoing adipogenic differentiation, also exhibits an inhibitory activity when supplied as a purified protein to MSC subjected to adipogenic stimuli, leading to markedly reduced levels of the AdipoQ and FABP4 markers. These findings are of pivotal relevance, as they unveil a role for Emilin-2 in the modulation and balance of osteogenic vs adipogenic differentiation of MSC, thus expanding the landscape of molecular players, different from cytokines and growth factors [35, 36], involved in their homeostasis and consequently in HSC modulation [4]. These data are also consistent with a number of literature studies showing that $\mathrm{BM}$ adipocytes are not simple tissue filler, but they act as critical regulators of HSC quiescence, proliferation and differentiation $[2,3,5]$.

Of note, in vivo ablation of Emilin-2 also affects hematopoiesis, since our data show that Emilin2 null mice display a progressive age-related drop of the frequency of hematopoietic progenitors, coupled with an expansion of the immature (Lin-) cell population and a decreased abundance of mature monocytes and lymphocytes when compared to wild-type mice. The defective capability of Emilin2 null mice to maintain hematopoiesis during aging may be related to a higher increase of adipose tissue in BM of Emilin-2 deficient animals, in agreement with the unbalanced adipogenic differentiation that is observed during aging [2]. Such aspect is worthy to be investigated in further detail in the future, also monitoring the respective activity of constitutive vs regulated $\mathrm{BM}$ adipose tissue, which are known to differently affect hematopoiesis and whose composition is dynamically regulated in response to a variety of physiological and pathological conditions [37].

The detailed understanding of mechanisms regulating adipogenic differentiation has increasing relevance not only in the physiological control of BM homeostasis, but also in the etiopathology of hematological malignancies, such as multiple myeloma [6,38-40], and in the recovery after tumor treatment with chemotherapy and radiotherapy cycles. Indeed, inhibition or induction of adipogenesis in BM was found to elicit positive and negative effects, respectively, in hematopoietic recovery after chemotherapy [5]. Radiotherapy treatment of different types of cancer, not directly related to bones, increases BM adipose tissue mass together with increased osteoclast activities, leading to worsening of bone parameters, such as trabecular bone volume, in both humans and rodents [41-44]. As a fibrillar component of ECM [45], it is conceivable that Emilin-2 may be involved in the regulation of BM biomechanical properties, which are well known modulators of MSC and HSC fate decision [46-48].

\footnotetext{
(See figure on next page.)

Fig. 4 Frequency of in vivo HSC and LT-HSC hematopoietic progenitors in adult wild-type and Emilin-2 null mice. BM were isolated from wild-type and Emilin2 ${ }^{-1-}$ mice of 3,6 and 10 months of age and subjected to flow cytometry with different antibodies. A Representative flow cytometry analysis of HSC and LT-HSC in BM of 10-month-old mice, based on the identification of lineage-negative (Lin ${ }^{-}$) cells and of Sca1, C-Kit, CD150 and CD48 markers. Live cells, identified with side scatter (SSC; granularity) and forward scatter (FSC; cell size) parameters (plot i), negative for Lin ${ }^{-}$marker (plot ii), were selected and analyzed for Scal and c-Kit signal (plot iii). Double positive Sca $1^{+} / \mathrm{c}-\mathrm{Kit}^{+}$events were identified as HSC (squared areas of plot iii) and subjected to further analysis based on CD150 and CD48 signals to identify LT-HSC (Cd150+/CD48- squared area of plot iv). B Percentages of HSC, calculated on total live cells and on Lin ${ }^{-}$cells, $n$ BM of 3-month-old (wild type, $n=4 ;$ Emilin2 $^{-1-}$, $n=4$ ), 6-month-old (wild-type, $n=10 ;$ Emilin2 $^{-1-}, n=6$ ) and 10-month-old (wild-type, $n=7 ;$ Emilin2 $^{-1-}, n=9$ ) mice. C Percentage of LT-HSC, calculated on either total live cells, Lin cells and HSC cells, in BM of 10-month-old (wild-type, $n=3 ;$ Emilin2 $^{-/-}, n=4$ ) mice
} 


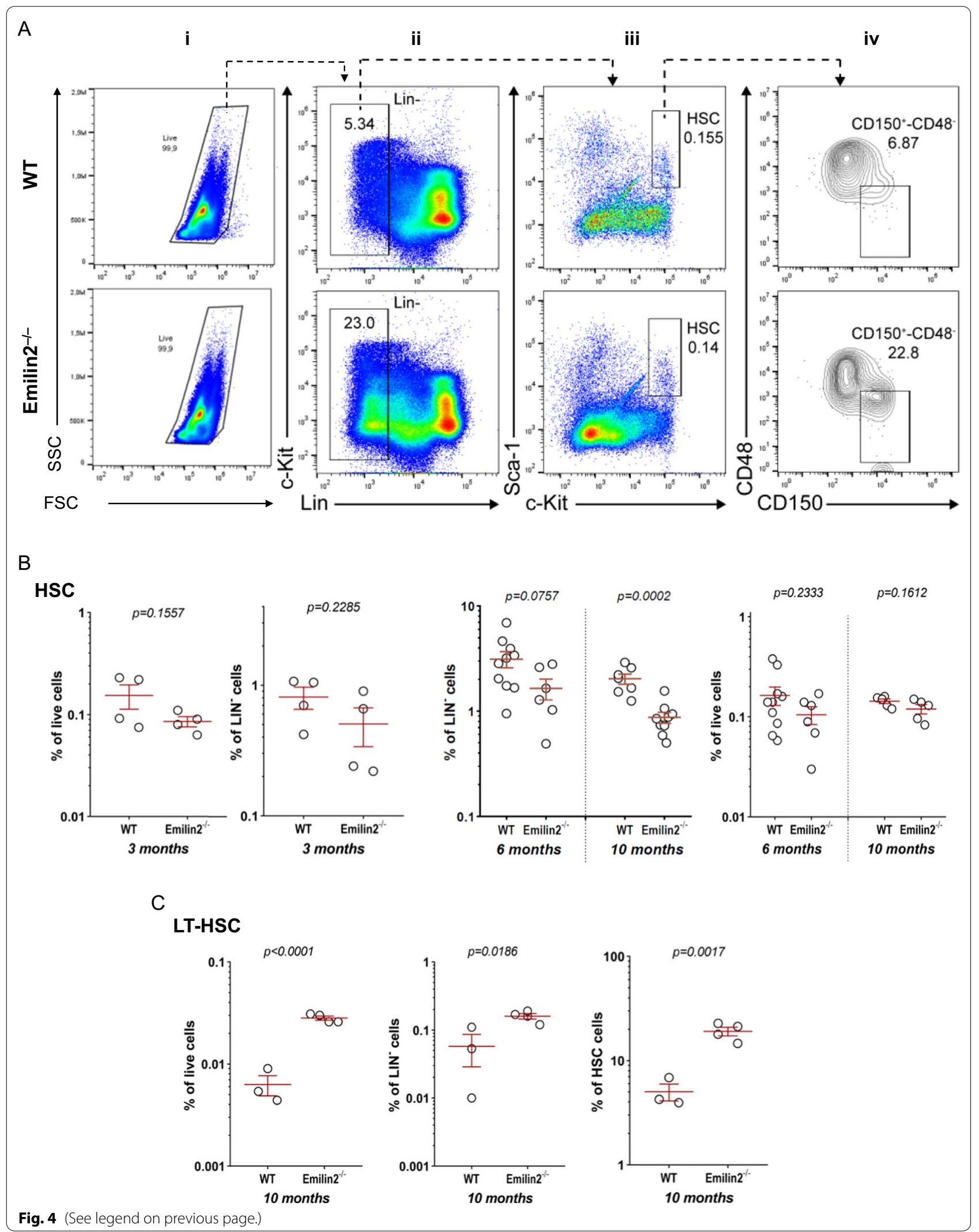




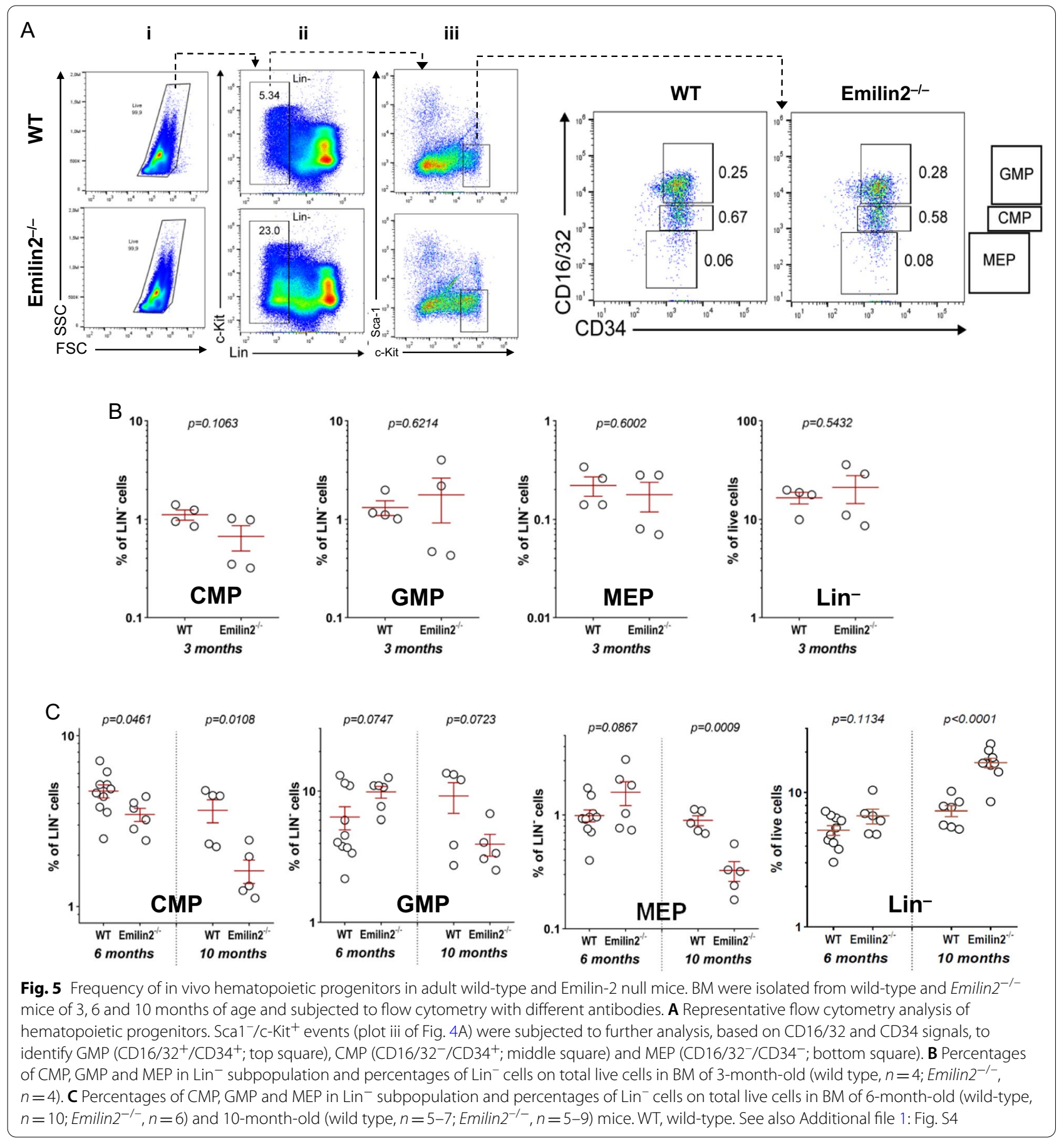

\section{Conclusions}

The present data throw light on the modulation of hematopoiesis by a distinctive ECM component of BM microenvironment, opening new perspectives about the role of this ECM protein in the onset and progression of BM disorders characterized by altered HPC frequency [9]. Indeed, the BM of Emilin2 null mice displays a decreased amount of CMP, GMP and MEP, and an expansion of immature cell populations. Literature work showed that deregulation of PU.1, a transcription factor mainly expressed by CMP and GMP, is a key molecular event in the initiation of AML [49]. Interestingly, in a comprehensive ChIP-Seq-based study for PU.1 target genes, Emilin2 was identified as a target gene of PU.1 


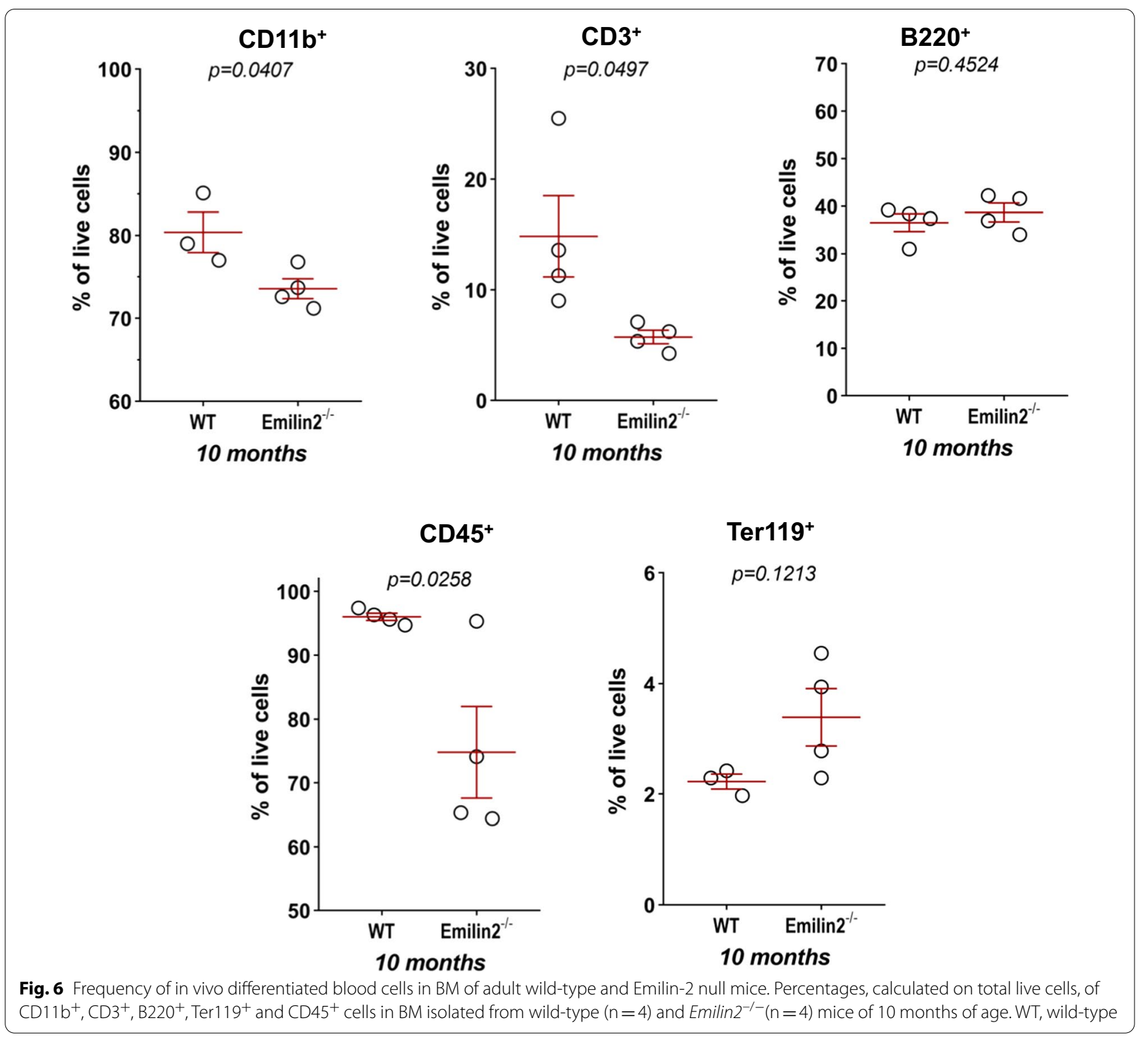

[50], thus suggesting a possible mechanistic relationship between Emilin-2 and occurrence of hematopoietic alterations in the BM. In addition, studies aimed at the characterization of the transcription profiles of ECM-related genes in AML patients identified Emilin2 as part of the signature of leukemia precursor cells and AML [23], thus pointing at an involvement of Emilin-2 in AML development. Of note, based on the analysis of RNA expression data in leukemia precursor cells, in AML cells and in the $\mathrm{BM}$ of AML patients, Emilin2 belongs to the group of most deregulated genes in AML patients [22, 23].

Altogether, our data show that Emilin-2, an ECM protein known to be involved in angiogenesis and tumor modulation [26-28], is a component of BM microenvironment involved in multiple functions in BM homeostasis, spanning from regulation of MSC differentiation to modulation of HSC pool and hematopoietic progenitor cell frequency. These findings pave the way for future studies aimed at dissecting in detail the roles of this ECM component in hematopoiesis sand its potential contribution in regulating adipocyte accumulation in BM during aging, as well as in the pathogenesis of MDS and AML. Such studies will provide valuable information for the detailed understanding of the roles of BM ECM in physiological and pathological conditions, and as well as for elucidating the contribution of distinct ECM players in the control of microenvironment and stem niches in BM tissue. 


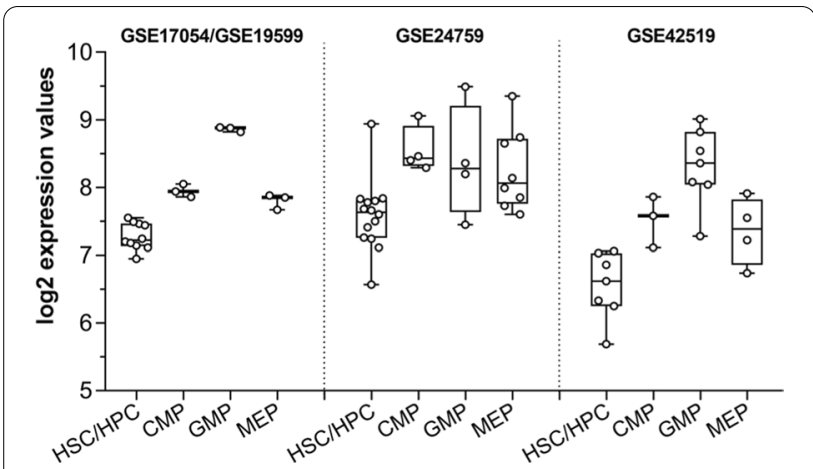

Fig. 7 Emilin-2 expression in human hematopoietic cells from publicly available datasets. Boxplot displaying the $\log _{2}$ transformed expression values for Emilin-2 in HSC, HPC and myeloid progenitors (CMP, GMP, MEP), as retrieved from different human hematopoietic (GSE17054, GSE19599, GSE24759, GSE42519) datasets. Normalized expression data were retrieved from BloodSpot database [54], without the application of any additional parameter

\section{Material and methods}

\section{Mice}

Wild-type and Emilin2 null mice in the C57/BL6N background [28] were bred in Specific Pathogen Free animal facility. The manipulation of animals and the harvest of organs were approved by an internal ethics committee and by the Italian Health Ministry (reference code D2784.N.XJY).

\section{Immunofluorescence}

Bones of 1-,3- and 6-month-old mice were fixed in 4\% paraformaldehyde at $4{ }^{\circ} \mathrm{C}$ overnight, washed in phosphate-buffered saline (PBS) and embedded in OCT after decalcification for two weeks with a 14\% EDTA solution. Ten $\mu \mathrm{m}$ slices were obtained with cryostat and processed for immunofluorescence. Slides of ST2 cells and primary MSC were fixed in 4\% paraformaldehyde at room temperature for $5 \mathrm{~min}$, washed in PBS and maintained at $4{ }^{\circ} \mathrm{C}$ until use. In brief, tissue slices were permeabilized using cold methanol/acetone for $5 \mathrm{~min}$, washed three times in PBS, and incubated for $1 \mathrm{~h}$ with $4 \%$ bovine serum albumin (BSA) in PBS, to block unspecific binding of the antibodies. Samples were incubated overnight at $4{ }^{\circ} \mathrm{C}$ with the following primary antibodies diluted with $1 \%$ BSA in PBS: guinea pig anti-Emilin-2 (1:200 [45], rabbit antiEmilin-2 (1:200 [45], rabbit anti-Collagen IV (1:200, Millipore). Slices were washed three times in PBS and then incubated for $1 \mathrm{~h}$ with the following secondary antibodies: anti-rabbit $\mathrm{Cy} 3$, anti-rabbit Cy5.5, anti-guinea pig Cy3 and anti-guinea pig 488 (all 1:400; Jackson ImmunoResearch). Hoechst 33258 (Invitrogen) was used for nuclear staining. After three washes in PBS, slices were mounted in glycerol $80 \%$.

\section{Cell culture and treatments}

The ST2 cell line was used as MSC surrogate [29] at passages from p3 to p5 and cultured in DMEM (Gibco), $10 \%$ fetal bovine serum (FBS), $1 \%$ glutamine, $1 \%$ penicillin/streptomycin. Primary BM-derived MSC were isolated from 4- to 8-week-old wild-type mice as described [51]. Primary cell cultures were maintained distinct for each experiment. Briefly, femur and tibia were cleaned from muscles and tendons and BM was flushed out with Alpha-MEM (Gibco) supplemented with $10 \%$ FBS, $1 \%$ penicillin/streptomycin, $1 \%$ glutamine and $10 \mathrm{ng} / \mathrm{ml}$ FGF2 [52]. After five days in culture, cells were split by incubation for 2 min with $0.25 \%$ trypsin (Invitrogen), to enrich the culture for MSC [51], and cultivated in the same medium. To induce adipogenic differentiation, ST2 cells and primary MSC were cultured for 10 days in Alpha-MEM supplemented with 10\% FBS, 1\% glutamine, $1 \%$ penicillin/streptomycin, $10^{-6} \mathrm{M}$ dexamethasone (Sigma), $50 \mu \mathrm{M}$ indomethacin (Sigma) and $0.5 \mathrm{mM}$ 3-isobutyl-1-methylxanthine (Sigma), changing the medium every three days. Where indicated, ST2 cells were plated for one day in the presence of purified Emilin-2 [28], added as soluble protein in culture medium at a final concentration of $200 \mathrm{ng} / \mathrm{ml}$. Oil Red O (Sigma) staining was performed after 18 days of adipogenic differentiation in BM-MSC as recommended by the manufacturer.

\section{Flow cytometry}

Flow cytometry was performed using CytoFLEX flow cytometer (Beckman Coulter) and FlowJo software (Tree Star). BM from femur and tibia was flushed with $5 \mathrm{ml}$ PBS using a 26/27G needle, and filtered through a $70-\mu \mathrm{m}$ cell strainer. The cell strainer was washed with other $3 \mathrm{ml}$ of PBS to increase yield, before centrifugation at 1,500 rpm for $5 \mathrm{~min}$. Erythrocytes were removed via hypotonic shock, by resuspending the pellet with $3 \mathrm{ml}$ of $0.2 \% \mathrm{NaCl}$ for $30 \mathrm{~s}$ and then adding an equal volume of $1.6 \% \mathrm{NaCl}$. BM cells were centrifuged at $1,500 \mathrm{rpm}$ for 5 min, resuspended in a solution of $90 \%$ FBS and $10 \%$ DMSO and maintained at $-80^{\circ} \mathrm{C}$ until analysis. Samples were stained for $30 \mathrm{~min}$ at room temperature with the following primary antibodies for cell membrane markers conjugated with fluorochrome, at a 1:100 dilution in PBS: anti-CD117(c-Kit)-PE, anti-Sca1-FITC, anti-CD16/32AF700, anti-CD34-eFluor660, anti-CD150-APC, anti-CD48-AF700 and Hematopoietic Lin Panel (CD11b, CD3e, CD45R/B220), Ly-6G, Ter-119)(all Life Technologies). After washing in PBS, when necessary samples were stained for 20 min with Pacific Blue-conjugated streptavidin (Life Technologies). Samples were then washed and resuspended in PBS for flow cytometry analysis. For 
HSC, LT-HSC, CMP, MEP and GMP analysis, gating was performed as described [53].

\section{Western blotting}

Cells and tissues were collected and lysed in $40 \mu \mathrm{l}$ RIPA buffer (20 mM Tris- $\mathrm{HCl}, \mathrm{pH}$ 7.5, $150 \mathrm{mM} \mathrm{NaCl}, 1 \mathrm{mM}$ EGTA, 1\% NP-40, 1\% sodium deoxycholate) supplemented with protease inhibitors (Roche) and phosphatase inhibitors (Sigma). Protein concentration was determined with the BCA Protein Assay (ThermoFisher). Protein extracts $(30-40 \mu \mathrm{g})$ were mixed with Novex Sample Buffer and Reducing Agent (Life Technologies), resolved by SDS-PAGE in $12 \%, 10 \%$ or $4-12 \%$ gradient gels and blotted onto polyvinylidene difluoride membranes (Millipore). Membranes were blocked for $1 \mathrm{~h}$ with $5 \%$ non-fat dry milk (Bio-Rad) or 5\% BSA in Tris-buffered saline containing $0.1 \%$ Tween 20 (TBS-T), and then incubated overnight at $4{ }^{\circ} \mathrm{C}$ with the following primary antibodies: mouse anti- $\beta$-actin (1:3000; Sigma-Aldrich); mouse anti-FABP4 (1:500, Santa Cruz Biotechnology); rabbit anti-adiponectin (1:1000; Thermo-Fisher Scientific); rabbit anti-Emilin-2 (1:1000 [45], antibody specificity shown in Additional file 1: Fig. S2F). After three washes for $10 \mathrm{~min}$ in TBS-T, membranes were incubated for $1 \mathrm{~h}$ with goat anti-mouse or anti-rabbit horseradish peroxidase-conjugated secondary antibodies (1:1000; Bethyl). After three further washes for $10 \mathrm{~min}$ in TBS-T, bands were detected with LiteAblot Extend chemiluminescent substrate (Euroclone), using a ImageQuantLAS 4000 digital imager (GE Healthcare).

\section{RNA extraction and RT-qPCR}

RNA was extracted from cell samples using TRIzol reagent as recommended by the manufacturer (Invitrogen). cDNA was synthesized from 0.5 to $1 \mu \mathrm{m}$ total RNA using M-MLV Reverse Transcriptase (Invitrogen). Real-time PCR reactions were performed using $5 \times$ HOT FirePol EvaGreen qPCR Mix Plus (Solys) and run with RotorGene Q (Qiagen). Each sample was loaded at least in duplicate and analyzed with the RotorGene Q 2.0.24 software (Qiagen). Forward and reverse primers used for amplification are listed in Additional file 1: Table S1. Rps 16 was used as internal control, in order to normalize differences in sample loading.

\section{Statistical analysis}

Data are presented as mean \pm s.e.m. The statistical significance was determined by unpaired two-tailed Student's $\mathrm{t}$ test, and $P$ values $<0.05$ were considered as significant. One-way Anova with Student Newman-Keuls Post hoc test was used for the comparison of multiple groups.

\section{Abbreviations}

AML: Acute myeloid leukemia; BM: Bone marrow; BSA: Bovine serum albumin; CMP: Common myeloid progenitors; ECM: Extracellular matrix; FBS: Fetal bovine serum; GMP: Granulocyte myeloid progenitors; HPC: Hematopoietic progenitor cells; HSC: Hematopoietic stem cells; Lin ${ }^{-}$: Lineage-negative; LTHSC: Long-term hematopoietic stem cells; MEP: Megakaryocyte-erythrocyte progenitors; MDS: Myelodysplastic syndromes; MSC: Mesenchymal stem cells; PBS: Phosphate-buffered saline; TBS-T: Tris-buffered saline containing $0.1 \%$ Tween 20

\section{Supplementary Information}

The online version contains supplementary material available at https://doi. org/10.1186/s13287-021-02674-2.

Additional file 1: Figure S1. Supporting immunofluorescence for Emilin-2 distribution, and specificity of the antibody against mouse murine Emilin-2. Related to Figs. 1, 2 and 3. (A) Digital reconstruction of sequential confocal microscopy images of Emilin-2 immunolabeling in femur sections of 6-month old wild-type mice. The red line on the left indicates compact bone area. Scale bar, $100 \mu \mathrm{m}$. (B) Magnification of vessels in BM of femur of 6-month old wild-type mice, following immunofluorescence for Emilin-2 (red) and Collagen IV (gray). Scale bar, 100 Hm. (E) Immunodetection of Emilin-2 (green) in BM section of femur of wild-type and Emilin2 $2^{-/-}$mice. Nuclei were stained with Hoechst (blue). Scale bar, $50 \mu \mathrm{m}$. (F) Western blot for Emilin-2 in protein extracts of primary BM-MSC (left panel) and BM tissue (right panel) collected from wild-type and Emilin2 ${ }^{-/}$ mice. $\beta$-actin and red ponceau were used as loading controls for BM-MSC and BM tissue, respectively. WT, wild-type. Figure S2. Schematic diagram of the different experimental approaches used for culture, differentiation and analysis of MSC. Related to Figs. 2 and 3. (A) Summary of the experiments with ST2 cells shown in Fig. 2A-D. (B) Summary of the experiments with ST2 cells shown in Fig. 2E, F. (C) Comparison of Emilin-2 mRNA levels between the two initial conditions of approach A (UT t0) and approach B (day 3, UT t0), as determined by RT-qPCR in untreated ST2 cells. mRNA levels are shown as fold change compared to UT t0 condition $(n=3$; **, $P<0.01$ ). (D) Summary of the experiments with ST2 cells shown in Fig. $2 F$. (E) Summary of the experiments with primary murine BM-MSC cultures shown in Fig. 3. Adipogenic stimulus is indicated with a flash above the horizontal line. Sample analysis is indicated with a small histogram below the horizontal line. d, days. Figure S3. Supporting data for Emilin-2 deposition during adipogenic differentiation. Related to Fig. 3. (A) Immunodetection of Emilin-2 at different timing of adipogenic differentiation of WT BM-MSC. Nuclei were stained with Hoechst (blue). Scale bar, $50 \mu \mathrm{m}$. (B) Western blot analysis of Emilin-2, following SDS-PAGE in 4-20\% gel, in primary BM-MSC at different time point during adipogenic differentiation. (C) Oil red $O$ staining for lipid droplet after 18 days in undifferentiating condition (UT t18) or adipogenic differentiation (Adipo t18). Scale bar, $50 \mu \mathrm{m}$. Figure S4. Supporting data for flow cytometry analyses of BM from WT and Emilin2 $2^{-/-}$mice. Related to Figs. 4 and 5. Schematic diagram of flow cytometry lineage markers used for HSC and HPC identification. Table S1. Primers used for RT-qPCR analyses. Related to Experimental Procedures and Figs. 2 and 3.

\section{Acknowledgements}

We are grateful to R. Wagener for the antibodies against murine Emilin-2, to A. Colombatti for the purified Emilin-2 protein and to E. Porcù and C. Frasson for technical help.

\section{Authors' contributions}

DRF, BP and BrP contributed to conceptualization; DRF, PL and BrP contributed to methodology; DRF, PL and BD performed investigation; DRF performed writing —original draft; DRF, BP, BrP and MM performed writing — review and editing; MM, MiM and BP contributed to funding acquisition; BP and MM performed supervision. All authors read and approved the final manuscript.

\section{Funding}

The project was supported by "Finchè ci sietevoi ci sono anche io" Associazione ONLUS(grant \# j31117000440007), CRO intramural grants (grant \# 
j32S16001310007), Alleanza Contro il Cancro (grant \# j34|20000600001), Associazione Italiana Contro Leucemie Linfomi e Mieloma (AIL), Pediatric Research Institute Foundation (grant \# IRP18/06), CARIPARO Foundation (grant \# 20/16 FCR), Italian Ministry of Health and Italian Ministry of University and Research.

\section{Availability of data and materials}

All data generated or analyzed during this study are included in this published article and its Additional file 1.

\section{Declarations}

\section{Ethics approval and consent to participate}

The manipulation of animals and the harvest of organs were approved by an internal ethics committee and by the Italian Health Ministry (reference code D2784.N.XJY).

\section{Consent for publication}

Not applicable.

\section{Competing interests}

The authors declare that they have no competing interests.

\section{Author details \\ 'sosd Cell Stem Unit, Department of Translational Research, National Cancer Center CRO-IRCSS, 33081 Aviano, Italy. ${ }^{2}$ Department of Molecular Medicine, University of Padova, Via Ugo Bassi 58/B, 35131 Padova, Italy. ${ }^{3}$ Department of Women's and Children's Health, University of Padova, 35131 Padova, Italy. ${ }^{4}$ IRP - Pediatric Research Institute, 35131 Padova, Italy. ${ }^{5}$ SOSd Cell Therapy and High Dose Chemotherapy, National Cancer Center CRO- IRCCS, 33081 Avi- ano, Italy. ${ }^{6} \mathrm{CRIBI}$ Biotechnology Center, University of Padova, 35131 Padova, Italy.}

\section{Received: 21 May 2021 Accepted: 9 October 2021}

Published online: 10 January 2022

\section{References}

1. Kfoury Y, Scadden DT. Mesenchymal cell contributions to the stem cell niche. Cell Stem Cell. 2015;16(3):239-53. https://doi.org/10.1016/j.stem. 2015.02.019.

2. Ambrosi TH, Scialdone A, Graja A, Gohlke S, Jank AM, Bocian C, Woelk L, Fan H, Logan DW, Schurmann A, et al. Adipocyte accumulation in the bone marrow during obesity and aging impairs stem cell-based hematopoietic and bone regeneration. Cell Stem Cell. 2017;20(6):77184. https://doi.org/10.1016/j.stem.2017.02.009.

3. Naveiras $O$, Valentina N, Wenzel P, Fahey F, Daley G. Bone marrow adipocytes as negative regulators of the hematopoietic microenvironment. Nature. 2009;460(9):259-63. https://doi.org/10.1002/maco.19800310308.

4. Wu J, Zhang W, Ran Q, Xiang Y, Zhong JF, Li SC, Li Z. The differentiation balance of bone marrow mesenchymal stem cells is crucial to hematopoiesis. Stem Cells Int. 2018;2018:1540148. https://doi.org/10.1155/ 2018/1540148.

5. Zhu RJ, Wu MQ, Li ZJ, Zhang Y, Liu KY. Hematopoietic recovery following chemotherapy is improved by BADGE-induced inhibition of adipogenesis. Int J Hematol. 2013;97(1):58-72. https://doi.org/10.1007/ s12185-012-1233-4

6. Liu H, He J, Koh SP, Zhong Y, Liu Z, Wang Z, Zhang Y, Li Z, Tam BT, Lin $P$, et al. Reprogrammed marrow adipocytes contribute to myelomainduced bone disease. Sci Transl Med. 2019;11(494):1-14. https://doi.org/ 10.1126/scitrans/med.aau9087.

7. Verma D, Zanetti C, Godavarthy PS, Kumar R, Minciacchi VR, Pfeiffer J, Metzler M, Lefort S, Maguer-Satta V, Nicolini FE, et al. Bone marrow nichederived extracellular matrix-degrading enzymes influence the progression of B-Cell acute lymphoblastic leukemia. Leukemia. 2020;34(6):154052. https://doi.org/10.1038/s41375-019-0674-7.

8. Wang J, Hendrix A, Hernot S, Lemaire M, DeBruyne E, VaNValckenborgh E, Lahoutte T, De Wever O, Vanderkerken K, Menu E. Bone marrow stromal cell-derived exosomes as communicators in drug resistance in multiple myeloma cells. Blood. 2014;124(4):555-66. https://doi.org/10.1182/ blood-2014-03-562439.

9. Shastri A, Will B, Steidl U, Verma A. Stem and progenitor cell alterations in myelodysplastic syndromes. Blood. 2017;129(12):1586-95. https://doi. org/10.1182/blood-2016-10-696062.1586.

10. Pang WW, Pluvinage JV, Price EA, Sridhar K, Arber DA, Greenberg PL, Schrier SL, Park CY, Weissman IL. Hematopoietic stem cell and progenitor cell mechanisms in myelodysplastic syndromes. Proc Natl Acad Sci USA. 2013;110(8):3011-6. https://doi.org/10.1073/pnas.1222861110.

11. Will B, Zhou L, Vogler TO, Ben-Neriah S, Schinke C, Tamari R, Yu Y, Bhagat TD, Bhattacharyya S, Barreyro L, Hueck C, et al. Stem and progenitor cells in myelodysplastic syndromes show aberrant stage-specific expansion and harbor genetic and epigenetic alterations. Blood. 2012;120(10):207686. https://doi.org/10.1182/blood-2011-12-399683.

12. Woll PS, Kjällquist U, Chowdhury O, Doolittle H, Wedge DC, Thongjuea S, Erlandsson R, Ngara M, Anderson K, Deng Q, et al. Myelodysplastic syndromes are propagated by rare and distinct human cancer stem cells in vivo. Cancer Cell. 2014;25(6):794-808. https://doi.org/10.1016/j.ccr. 2014.03.036.

13. Carter DH, Sloan P, Aaron JE. Immunolocalization of collagen types I and III, tenascin, and fibronectin in intramembranous bone. J Histochem Cytochem. 1991;39(5):599-606. https://doi.org/10.1177/39.5.1707904.

14. Gupta BP, Oegema TR Jr, Brazil JJ, Dudek AZ, Slungaard A, Verfaillie CM. Structurally specific heparan sulfates support primitive human hematopoiesis by formation of a multimolecular stem cell niche. Blood. 1998;92(12):4641-52.

15. Klein G, Müller CA, Tillet E, Chu ML, Timpl R. Collagen type VI in the human bone marrow microenvironment: a strong cytoadhesive component. Blood. 1995;86(5):1740-8.

16. Malara A, Currao M, Gruppi C, Celesti G, Viarengo G, Buracchi C, Laghi L, Kaplan DL, Balduini A. Megakaryocytes contribute to the bone marrowmatrix environment by expressing. Stem Cells. 2014;32(4):926-37. https:// doi.org/10.1002/stem.1626.

17. Nakamura-Ishizu A, Okuno Y, Omatsu Y, Okabe K, Morimoto J, Uede T, Nagasawa T, Suda T, Kubota Y. Extracellular matrix protein tenascin-C is required in the bone marrow microenvironment primed for hematopoietic regeneration. Blood. 2012;119(23):5429-37. https://doi.org/10.1182/ blood-2011-11-393645.

18. Nilsson SK, Debatis ME, Dooner MS, Madri JA, Quesenberry PJ, Becker PS. Immunofluorescence characterization of key extracellular matrix proteins in murine bone marrow in situ. J Histochem Cytochem. 1998;46(3):371-7. https://doi.org/10.1177/002215549804600311.

19. Schofield KP, Gallagher JT, David G. Expression of proteoglycan core proteins in human bone marrow stroma. Biochem J. 1999:343(Pt 3):663-8.

20. Sidhu I, Barwe SP, Gopalakrishnapillai A. The extracellular matrix: a key player in the pathogenesis of hematologic malignancies. Blood Rev. 2020:48: 100787. https://doi.org/10.1016/j.blre.2020.100787.

21. Naba A, Clauser KR, Hoersch S, Liu H, Carr SA, Hynes RO. The matrisome. In: Silico definition and in vivo characterization by proteomics of normal and tumor extracellular matrices. Molecular and Cellular Proteomics. 2012. 11 (4): 1-18. https://doi.org/10.1074/mcp.M111.014647

22. Çelik H, Lindblad KE, Popescu B, Gui G, Goswami M, Valdez J, DeStefano C, Lai C, Thompson J, Ghannam JY, et al. Highly multiplexed proteomic assessment of human bone marrow in acute myeloid leukemia. Blood Adv. 2020;4(2):367-79. https://doi.org/10.1182/bloodadvances.20190 01124.

23. Izzi V, Lakkala J, Devarajan R, Ruotsalainen $H$, Savolainen ER, Koistinen P, Heljasvaara R, Pihlajaniemi T. An extracellular matrix signature in leukemia precursor cells and acute myeloid leukemia. Haematologica. 2017;23(4):471-3. https://doi.org/10.1097/GME.0000000000000638.

24. Braghetta P, Ferrari A, De Gemmis P, Zanetti M, Volpin D, Bonaldo P, Bressan GM. Overlapping, complementary and site-specific expression pattern of genes of the EMILIN/Multimerin family. Matrix Biol. 2004;22(7):549-56. https://doi.org/10.1016/j.matbio.2003.10.005.

25. Colombatti A, Spessotto P, Doliana R, Mongiat M, Bressan GM, Esposito G. The EMILIN/multimerin family. Front Immunol. 2012;2:93. https://doi.org/ 10.3389/fimmu.2011.00093.

26. Mongiat M, Ligresti G, Marastoni S, Lorenzon E, Doliana R, Colombatti A. Regulation of the extrinsic apoptotic pathway by the extracellular matrix glycoprotein EMILIN2. Mol Cell Biol. 2007;27(20):7176-87. https://doi.org/ 10.1128/MCB.00696-07. 
27. Mongiat M, Marastoni S, Ligresti G, Lorenzon E, Schiappacassi M, Perris $R$, Frustaci S, Colombatti A. The extracellular matrix glycoprotein elastin microfibril interface located protein 2: a dual role in the tumor microenvironment. Neoplasia. 2010;12(4):294-304. https://doi.org/10.1593/neo. 91930.

28. Paulitti A, Andreuzzi E, Bizzotto D, Pellicani R, Tarticchio G, Marastoni S, Pastrello C, Jurisica I, Ligresti G, Bucciotti F, et al. The ablation of the matricellular protein emilin2 causes defective vascularization due to impaired EGFR-dependent IL-8 production affecting tumor growth. Oncogene. 2018;37(25):3399-414. https://doi.org/10.1038/s41388-017-0107-x.

29. Abdallah BM, Alzahrani AM, Abdel-Moneim AM, Ditzel N, Kassem M. A simple and reliable protocol for long-term culture of murine bone marrow stromal (mesenchymal) stem cells that retained their in vitro and in vivo stemness in long-term culture. Biol Proced Online. 2019;21(1):111. https://doi.org/10.1186/s12575-019-0091-3.

30. Klamer S, Voermans C. The role of novel and known extracellular matrix and adhesion molecules in the homeostatic and regenerative bone marrow microenvironment. Cell Adh Migr. 2014;8(6):563-77. https://doi.org/ 10.4161/19336918.2014.968501.

31. Anthony BA, Link DC. Regulation of hematopoietic stem cells by bone marrow stromal cells. Trends Immunol. 2014;35(1):32-7. https://doi.org/ 10.1016/j.it.2013.10.002.

32. Birbrair A, Frenette PS. Niche heterogeneity in the bone marrow. Ann NY Acad Sci. 2016;1370(1):82-96. https://doi.org/10.1111/nyas.13016.

33. Zhao M, Li LH. Regulation of hematopoietic stem cells in the niche. Science China Life Sciences. 2015;58(12):1209-15. https://doi.org/10.1007/ s11427-015-4960-y.

34. Kramer AC, Blake AL, Taisto ME, Lehrke MJ, Webber BR, Lund TC. Dermatopontin in bone marrow extracellular matrix regulates adherence but is dispensable for murine hematopoietic cell maintenance. Stem Cell Rep. 2017;9(3):770-8. https://doi.org/10.1016/j.stemcr.2017.07.021.

35. Kang Q, Song WX, Luo Q, Tang N, Luo J, Luo X, Chen J, Bi Y, He BC, Park JK, et al. A comprehensive analysis of the dual roles of BMPs in regulating adipogenic and osteogenic differentiation of mesenchymal progenitor cells. Stem Cells Dev. 2009;18(4):545-58. https://doi.org/10.1089/scd. 2008.0130.

36. Stevens JR, Miranda-Carboni GA, Singer MA, Brugger SM, Lyons KM, Lane TF. Wnt10b deficiency results in age-dependent loss of bone mass and progressive reduction of mesenchymal progenitor cells. J Bone Miner Res. 2010;25(10):2138-47. https://doi.org/10.1002/jbmr.118.

37. Scheller EL, Doucette CR, Learman BS, Cawthorn WP, Khandaker S, Schell B, Wu B, Ding SY, Bredella MA, Fazeli PK, et al. Region-specific variation in the properties of skeletal adipocytes reveals regulated and constitutive marrow adipose tissues. Nat Commun. 2015;6:7808. https://doi.org/10. 1038/ncomms8808.

38. Liu Z, Xu J, He J, Liu H, Lin P, Wan X, Navone NM, Tong Q, Kwak LW, Orlowski RZ, et al. Mature adipocytes in bone marrow protect myeloma cells against chemotherapy through autophagy activation. Oncotarget. 2015;6(33):3429-41. https://doi.org/10.18632/oncotarget.6020.

39. Morris EV, Edwards CM. Adipokines, adiposity, and bone marrow adipocytes: dangerous accomplices in multiple myeloma. J Cell Physiol. 2018;233(12):9159-66. https://doi.org/10.1002/jcp.26884.

40. Trotter TN, Gibson JT, Sherpa TL, Gowda PS, Peker D, Yang Y. Adipocytelineage cells support growth and dissemination of multiple myeloma in bone. Am J Pathol. 2016;186(11):3054-63. https://doi.org/10.1016/j. ajpath.2016.07.012.

41. Costa S, Reagan MR. Therapeutic irradiation: consequences for bone and bone marrow adipose tissue. Front Endocrinol. 2019;10:587. https://doi. org/10.3389/fendo.2019.00587.

42. Curi MM, Cardoso CL, De Lima HG, Kowalski LP, Martins MD. Histopathologic and histomorphometric analysis of irradiation injury in bone and the surrounding soft tissues of the jaws. J Oral Maxillofac Surg. 2016;74(1):190-9. https://doi.org/10.1016/j.joms.2015.07.009.

43. Green DE, Adler BJ, Chan ME, Lennon JJ, Acerbo AS, Miller LM, Rubin CT. Altered composition of bone as triggered by irradiation facilitates the rapid erosion of the matrix by both cellular and physicochemical processes. PLoS ONE. 2013;8(5): e64952. https://doi.org/10.1371/journal. pone.0064952.

44. Zou Q, Hong W, Zhou Y, Ding Q, Wang J, Jin W, Gao J, Hua G, Xu X. Bone marrow stem cell dysfunction in radiation-induced abscopal bone loss. J Orthop Surg Res. 2016;11(1):1-10. https://doi.org/10.1186/ s13018-015-0339-9.

45. Schiavinato A, Keene DR, Wohl AP, Corallo D, Colombatti A, Wagener R, Paulsson M, Bonaldo P, Sengle G. Targeting of EMILIN-1 and EMILIN-2 to fibrillin microfibrils facilitates their incorporation into the extracellular matrix. J Investig Dermatol. 2016;136(6):1150-60. https://doi.org/10. 1016/j.jid.2016.02.021.

46. Choi JS, Harley BAC. Marrow-inspired matrix cues rapidly affect early fate decisions of hematopoietic stem and progenitor cells. Sci Adv. 2017;3(1): e1600485. https://doi.org/10.1126/sciadv.1600455.

47. Shin JW, Swift J, Ivanovska I, Spinler KR, Buxboim A, Discher DE. Mechanobiology of bone marrow stem cells: from myosin-Il forces to compliance of matrix and nucleus in cell forms and fates. Differentiation. 2013;86(3):77-86. https://doi.org/10.1016/j.diff.2013.05.001.

48. Zhang P, Zhang C, Li J, Han J, Liu X, Yang H. The physical microenvironment of hematopoietic stem cells and its emerging roles in engineering applications. Stem Cell Res Ther. 2019;10(1):327. https://doi.org/10.1186/ s13287-019-1422-7.

49. Will B, Vogler TO, Narayanagari S, Bartholdy B, Todorova TI, Da Silva Ferreira M, Chen J, Yu Y, Mayer J, Barreyro L, et al. Minimal PU1 reduction induces a preleukemic state and promotes development of acute myeloid leukemia. Nat Med. 2015;21(10):1172-81. https://doi.org/10.1038/nm.3936.

50. Satoh J, Asahina N, Kitano S, Kino Y. A comprehensive Chip-Seq-based PU1/Spi1 target genes in microglia. Syst Biol. 2014;3(2):159-79. https:// doi.org/10.4137/GRSB.S1971.

51. Huang S, Xu L, Sun Y, Wu T, Wang K, Li G. An improved protocol for isolation and culture of mesenchymal stem cells from mouse bone marrow. J Orthop Transl. 2015;3(1):26-33. https://doi.org/10.1016/j.jot.2014.07.005.

52. Caroti CM, Ahn H, Salazar HF, Joseph G, Sankar SB, Willett NJ, Wood LB, Taylor WR, Lyle AN. A novel technique for accelerated culture of murine mesenchymal stem cells that allows for sustained multipotency. Sci Rep. 2017;7(1):1-14. https://doi.org/10.1038/s41598-017-13477-y.

53. Tang F, Zhang P, Ye P, Lazarski CA, Wu Q, Bergin IL, Bender TP, Hall MN, Cui $Y$, Zhang $L$, et al. A population of innate myelolymphoblastoid effector cell expanded by inactivation of MTOR complex 1 in mice. Elife. 2017:6:1-30. https://doi.org/10.7554/eLife.32497.

54. Bagger FO, Kinalis S, Rapin N. BloodSpot: a database of healthy and malignant haematopoiesis updated with purified and single cell mRNA sequencing profiles. Nucleic Acids Res. 2019;47(D1):D881-5. https://doi. org/10.1093/nar/gky1076.

\section{Publisher's Note}

Springer Nature remains neutral with regard to jurisdictional claims in published maps and institutional affiliations.

Ready to submit your research? Choose BMC and benefit from

- fast, convenient online submission

- thorough peer review by experienced researchers in your field

- rapid publication on acceptance

- support for research data, including large and complex data types

- gold Open Access which fosters wider collaboration and increased citations

- maximum visibility for your research: over $100 \mathrm{M}$ website views per year

At $\mathrm{BMC}$, research is always in progress.

Learn more biomedcentral.com/submissions 